\title{
Proposta epistemológica para uma visão decolonial da Bíblia
}

\author{
Propuesta epistemológica para una \\ mirada decolonial de la Biblia \\ Epistemological proposal for a decolonial \\ view of the Bible
}

\section{Resumo}

Os tempos contemporâneos exigem que o conhecer emerja de outros paradigmas. Os estudos bíblicos como provocadores de conhecimentos demandam abordagens complexas, que possibilitem desvelar as interações tanto internas ao texto como aquelas a partir das quais se lê ou interpreta. Neste ensaio, partindo da crítica a um pensamento simplista e colonial, com o qual muitas vezes se leem e se interpretam os textos, fruto do colonialismo e da destruição dos conhecimentos que este realizou em meio aos povos, se faz uma proposta epistemológica tomando a complexidade como enfoque dinâmico e multidimensional, que convida a abandonar a ideia de sistemas estanques para a geração de um conhecimento, que surge de e promove aprendizagens e pedagogias libertadoras. Para tais fins, me apoiarei, entre outros, de autoras como Denisse Najmanovich $(2005,49)$, que reconhece que "las perspectivas clásicas invisibilizan las interacciones, se restringen a explorar lo diverso, lo creativo, lo no domesticable, lo que se inscribe como acontecimiento y no puede fosilizarse en un modelo". Esta constatação da autora me motiva e me facilita elementos para criticar os estudos bíblicos feitos com os métodos tradicionais de leitura que limitam as interpretações ao texto e a seu contexto, deixando de lado a experiência e a localização epistemológica e sociopolítica de quem lê.

Palavras-chave: estudos bíblicos; epistemologia; complexidade; pedagogia; aprendizagem; decolonial.

${ }^{1}$ Dra. en Biblia, énfasis en el Primer Testamento. Doctoranda en Educación y Mediación Pedagógica, Docente investigadora en la Universidad de la Salle, San José, Costa Rica, 


\title{
Resumen
}

Los tiempos contemporáneos exigen que el conocer emerja desde otros paradigmas. Los estudios bíblicos como provocadores de conocimientos demandan abordajes complejos, que posibiliten develar las interacciones tanto internas al texto como aquellas desde donde se lee o interpreta. En este ensayo, desde la crítica a un pensamiento simplista y colonial, con el que muchas veces se leen e interpretan los textos, fruto del colonialismo y la destrucción de los conocimientos que este ha causado a los pueblos, se hace una propuesta epistemológica tomando la complejidad como enfoque dinámico y multidimensional, que invita abandonar la idea de sistemas aislados para la generación de un conocimiento, que surge de y promueve aprendizajes y pedagogías liberadoras. Para tales fines, me apoyaré, entre otros, de autoras como Denisse Najmanovich (2005, 49), quien reconoce que "las perspectivas clásicas invisibilizan las interacciones, se restringen a explorar lo diverso, lo creativo, lo no domesticable, lo que se inscribe como acontecimiento y no puede fosilizarse en un modelo". Esta constatación de la autora me motiva y me facilita elementos para criticar los estudios bíblicos hechos desde los métodos tradicionales de lectura que limitan las interpretaciones al texto y su contexto, dejando de lado la experiencia y la localización epistemológica y sociopolítica de quien lee.

Palabras-clave: estudios bíblicos; epistemología; complejidad; pedagogía; aprendizaje; decolonial.

\begin{abstract}
Knowledge emerges from other paradigms as a must in current times. Biblical studies as knowledge provoking demand complex approaches which allow the revelation of the internal interactions from the text and those from where it is read or interpreted. In this essay, from the critics of a simplistic and colonial thought, with which the texts are often read and interpreted, which is the result of colonialism and the destruction of the knowledge that it has caused to the peoples, is presented a epistemological proposal and, tacking the approach of complexity as dynamic and multidimensional. This approach invites to abandon the idea of isolated systems for the generation of a knowledge that emerges from and promotes liberation learnings and pedagogies. For this purpose, I leaned on, Denisse Najmanovich $(2005,49)$, who recognizes that "the classic perspectives invisibilize the interactions, but they limit themselves to explore diversity, creativity, the undomestical and what is not inscribed as un event that cannot be fossilized as a model". The author statement, motivates me and at the same time, it facilitates me elements to criticize the Biblical studies carried out from traditional reading methodologies that limit the interpretations of the text and its context, leaving aside the experience and the epistemology and socio-politics of the reader.
\end{abstract}

Keywords: Bible studies; epistemology; complexity; pedagogy; learning; decolonial. 


\section{Al inicio de la propuesta - constataciones y preguntas}

Los escritos bíblicos...ofrecen muchos ejemplos de procesos interpretativos, pero pocos aspectos teóricos, por no decir ninguno (John Barton 2001, p. 121).

Los denominados estudios bíblicos, al igual que otras formas de conocer, son una construcción social y dependen tanto de las creencias y valores de quienes leen como de su apego a métodos e interpretaciones. La propuesta epistemológica y la perspectiva pedagógica constituyen dos elementos clave para reflexionar sobre una mirada crítica de la Biblia y el aprendizaje que resulta de esta manera de trascender las aproximaciones tradicionales, pero cuestionar también aquellas lecturas bíblicas que, sin alejarse de un paradigma estandarizador, donde todo está predeterminado, se llaman liberadoras. En este sentido, este ensayo es una propuesta que invita a reflexionar desde un pensamiento otro. Un pensamiento que permita una práctica de lectura de la biblia que se aleje de la reproducción del colonialismo tanto en las mentalidades como en las subjetividades, en la cultura y en la epistemología.

En muchos lugares de América Latina y Caribe: desde la propuesta de la teología de la liberación, la Biblia se reconoce en su aspecto social, en relación con las lecturas e interpretaciones hechas desde las perspectivas de los grupos en condiciones de vulnerabilidad: pobres, mujeres, pueblos originarios, afrodescendientes, personas con opciones sexuales no normatizadas, entre otros. Sin embargo, el conocimiento producido por estas interpretaciones, pocas veces se entiende como propuesta epistemológica de transformación, dentro de ámbitos sociales más amplios como es, por ejemplo, el de la educación. De ahí, la necesidad de colocar los estudios bíblicos más allá de los conocimientos de casa, entiéndase, al interior de las iglesias o las comunidades cristianas, las facultades de teología o los institutos relacionados con el campo de la religión, sino en diálogo con otras disciplinas, con otras formas de conocimiento. Los estudios bíblicos pueden enseñar de valores y de acciones liberadoras desde un pensamiento, que continúe priorizando lo cotidiano, pero desde una propuesta de pensamiento compleja, y desde ahí, prestar atención a las interacciones entre los espacios privados y otros ámbitos sociales. Colocarlos en los espacios de pensar sobre el conocer y en las implicaciones que esto tiene, en la sociedad en general, ya sea en términos pedagógicos como de construcción de aprendizajes.

Es por lo que, para esta reflexión, se hace necesario una mirada diferente sobre el pensamiento mecanicista: una crítica al sistema patriarcal, así como una crítica al pensamiento racional y su linealidad (Capra 2008, pp. 21-53), lo que permite reconocer el peligro de una lectura de la bíblica que robotiza. En este sentido, el diálogo con distintos autores me aportará 
los elementos básicos para formular una propuesta epistemológica capaz de dialogar de una forma diferente con los textos bíblicos y con algunas interpretaciones bíblicas, propuestas por diferentes autoras y autores que considero significativas, dentro del campo bíblico, así como de otras disciplinas.

De Paulo Freire, hemos aprendido la importancia de formular preguntas dentro de un proceso de aprendizaje, me permiten detenerme y presentar las preguntas que motivan esta reflexión: ¿cómo repensar los estudios bíblicos a partir de la propuesta de una nueva visión de la ciencia y, principalmente, de una evolución de la educación? ¿Cómo pueden estar vinculadas las llamadas crisis de la religión con la falta de una lectura de la Biblia hecha de una forma más integral y compleja? ¿De qué manera quien lee los textos bíblicos puede enfrentar la tensión entre la supuesta "objetividad" que exige el llamado método histórico-crítico y su propia "subjetividad y la de los otros actores participantes en la lectura? En definitiva, cuando repaso cada una de estas preguntas quiero dejar explicita el tener presente la complejidad de los procesos. Y es como proceso que entiendo la formulación de una propuesta epistemológica en torno a una mirada crítica desde y hacia la Biblia.

Se trata de un proceso que se genera a partir de preguntas sin, necesariamente, esperar respuestas acabadas. Paulo Freire (1996, p. 55) expresa su pensar en este sentido, cuando afirma que "históricosocioculturales, mujeres y hombres nos volvemos seres en quienes la curiosidad, ultrapasando los límites que le son peculiares en el dominio vital, se vuelve fundante de la producción del conocimiento. Y más todavía, la curiosidad es ya conocimiento". Plantear estas mis preguntas, es ya conocimiento. Pues surge de la conciencia del inacabamiento del proceso de estudiar la Biblia. Significa, no todo está dicho. Y más todavía, no se pretende con este ensayo decir todo.

La cita que precede este inicio, quiere ser un llamado de atención a las limitaciones que pueden ser contactadas en los estudios Bíblicos. Una de esas limitaciones es la falta de teoría que, al entender de John Barton (2001, p.139) puedan explicar de qué forma los escritos bíblicos acaban siendo utilizados de forma manipuladora para dar validez a nuevas estructuras de poder. Sin embargo, es importante tener presente, así como afirma Edgar Morin (2009, p. 25) que "una teoría no es el conocimiento, sino que permite el conocimiento. Una teoría no es una llegada es la posibilidad de una partida. Una teoría no es una solución, es la posibilidad de tratar un problema. Una teoría sólo cumple su papel cognitivo, sólo adquiere vida, con el pleno empleo de la actividad mental del sujeto."

En este sentido, las preguntas formuladas, me permiten conectar con el sentido de educación en la que creo. Una educación centrada en la pregunta y mucho menos en la respuesta. Una educación donde se van construyendo puertas mientras intento salir de presupuestos 
epistemológicos acabados y fijos de los estudios bíblicos e ir hacia espacios movidos por las incertezas que crea el propio conocimiento de los textos bíblicos, pero que animan a despertar de una sociedad-mundo prefijada, mecanicista. Pero para esto, es necesario reflexionar sobre algunas de las características que tienen los estudios bíblicos en América Latina su herencia y sus aportes en términos pedagógicos.

\section{La Lectura de la Biblia en América Latina - de su herencia y aportes pedagógicos}

Invoco la presencia de nuestros cuerpos en la lectura de la Biblia, los ojos, sí, pero también los otros sentidos, encontrar los sabores, los olores, las texturas y los sonidos de este mundo extraño $y$, a la vez, parecido al nuestro. (Seibert Cuadra, 2003)

Es importante destacar que la lectura de la Biblia ha estado marcada generalmente por los intereses religiosos o, más concretamente, por aspectos teológicos conservadores. Desde esta perspectiva teológica, desde una particularidad eurocéntrica se pretende poseedora de un conocimiento absoluto. En este sentido, Robert Morgan (1998, p. 140) entiende que la interpretación bíblica tradicionalmente hace referencia al proceso intelectual de expresar una fe y una práctica religiosa relacionando una tradición religiosa autoritativa con el conocimiento y la experiencia contemporáneos, y viceversa. Sin embargo, cuando pienso en y desde América Latina, puedo destacar dos caminos que marcan la herencia de los estudios e interpretación de la Biblia. Por un lado, una interpretación marcada por intereses teológicos conservadores, donde se ha pensado la Biblia como un depósito de la verdad y de la salvación.

Desde esa manera de leer el texto bíblico los saberes, las prácticas, la vida de las personas que leen son considerados signos de impotencia para ser otra cosa que no sea obedecer "la palabra de dios". Dicho de otra manera, la Palabra de Dios es, primero, enclaustrada en el texto y, segundo, puesto el texto por encima de la propia vida. Por lo tanto, no hay otro camino que el de la obediencia al texto, siempre con el objetivo de la salvación. Es desde esa realidad que se afirma que la gran mayoría de las personas cristianas y la mayor parte de las iglesias tienen una manera conservadora y, hasta fundamentalista, de mirar la Biblia (Mesters y Orofino, 2012). Por otro lado, debo reconocer la no linealidad en los estudios bíblicos, cuando estos mismos autores destacan el impacto y la irradiación de la lectura hecha en las Comunidades Eclesiales (CEBs). En estas experiencias de Comunidades, la teología que las mueve es liberadora, es decir, una teología en tanto reflexión crítica de la praxis histórica es acto segundo (Gutiérrez, 1975). Es por esto, que la reflexión de Ute Seibert Cuadra me 
refresca al permitirme sentir mi propio cuerpo antes del texto, en conexión con los sonidos que siento y percibo más allá de mi misma.

En varias ocasiones, Milton Schwantes (1992) afirmó, la vida de las personas, los dolores, utopías y poesías de los pobres se tornaron, a través de las comunidades, mediaciones hermenéuticas decisivas para la lectura bíblica en América Latina y en el Caribe. Cuando se lee la Biblia en la comunidad y como comunidad, se hace a partir de la propia historia: las tristezas, alegrías y sueños de vida de quienes leen el texto. Es así que surge la lectura popular de la Biblia. Una lectura realizada por el pueblo de las comunidades. Se trata del pueblo que representa el grupo subordinado en una sociedad organizada kiriarquicamente ${ }^{2}$. Pero que además es consciente de la situación en que se encuentra.

Por eso, podemos decir que una lectura popular, es aquella que parte de la vida misma de las personas que hacen la lectura bíblica y que intentan entender los códigos presentes en el texto a partir de esta vida. Siempre con la tarea de poder dialogar con el texto y a partir de aquí proponer transformaciones concretas. Este pueblo, al entender de Mesters y Orofino (2012), encuentra en la Biblia como un espejo de lo que él mismo vive, estableciendo, entonces, una relación profunda entre la Biblia y la vida de las personas. Sin embargo, no siempre los textos bíblicos traen palabras de aliento, por eso Elsa Tamez (2004, pp. 13-14), refiriéndose a la Primera Carta de Timoteo, afirma "la lectura de la Biblia desde la perspectiva de las personas excluidas no encuentran en esta carta, como en otros libros de la Biblia, palabras de aliento y esperanza que los animen a sobrellevar y resistir la vida difícil a la cual se enfrentan en medio de la pobreza y la discriminación".

Es por esto, que durante mucho tiempo se entendió que la teología de la liberación ha marcado, en América Latina, un antes y un después en los estudios bíblicos. Pues ella posibilitó una lectura de la Biblia centrada en el ver, juzgar y actuar, permitiendo no sólo leer pensando en las personas económicamente más vulnerables, sino desde ellas mismas, por ellas mismas. Pero, al mismo tiempo, esto abrió las puertas para lecturas más radicales, como son la lectura en clave campesina, que como bien afirma Aníbal Cañaveral (2011, p. 31) “es una lectura desde la óptica de los pueblos campesinos, tal cual ellos se expresan en sus diferentes contextos latinoamericanos y caribeños... Una lectura que propone y se propone desde un escarbar vital, con lo cual apunta a la manera de obtener un fruto vital de la madre Tierra para alimentarnos".

Por su parte, Maricel Mena (2005, pp. 130-134), propone un cambio de paradigma a partir de una hermenéutica negra feminista

\footnotetext{
${ }^{2}$ Término propuesto por Elisabeth Schüsler Fiorenza (2000, 32), para referirse al concepto patriarcado que no signifique solamente que los hombres rigen a las mujeres, sino que se refiera a una compleja pirámide social de dominaciones y subordinaciones graduadas. Kiriarcado, que significa el gobierno del emperador/amo/señor/padre/esposo sobre sus subordinados.
} 
latinoamericana. Esa autora afirma que "desde el punto de vista teológico, la "historia oficial" de corte eurocéntrico ha hecho de todo para negar cualquier influencia africana en la historia de Israel y en los orígenes del cristianismo". ¿Por esta razón, la autora se pregunta "cómo podemos las mujeres negras reconstruir nuestra identidad a partir de esa "verdad" revelada en la Biblia? Y yo diría, no sólo reconstruir nuestra identidad como mujeres negras, sino también al interpretar los textos bíblicos siendo mujeres negras interesadas por otras miradas. Es por eso que planteo, en una reflexión a partir de Jeremías 38 que: "mi punto de partida es el propio texto que en su contenido, apunta para mirar y escuchar otras voces diferentes a las del profeta Jeremías. Invitamos a escuchar la voz de Ebedmelek, el cuchita, quien actúa precisamente para salvar al profeta" (Ventura, 2006, pp. 61-74).

En el mismo sentido, Jose Luiz Izidoro (2013, p. 7), afirma que "la formación y la construcción de los textos sagrados que componen la biblioteca bíblica resultan de un proceso histórico-literario en el cual culturas, etnias, religiones y sociedades están presentes mediante representaciones simbólicas, lenguajes, discursos y otras convenciones en contacto". Sin olvidar, las distintas maneras de leer la Biblia que desde hace más de dos décadas las mujeres, en América Latina y el Caribe vienen proponiendo, por medio de la hermenéutica feminista, que al entender de Ivone Gebara (1994, p. 30) "se presenta como una manera de interpretar un texto, comprendiendo la existencia de las mujeres, sus esperanzas, sus gritos de dolor, su complicidad con el mal del mundo y su manera de buscar un rostro nuevo para la sociedad".

Todo esto, sólo para mencionar algunos autores y autoras que han traído frescor a la interpretación de los textos bíblicos en América Latina y Caribe. Y esta frescura se genera prestando atención a grupos fuera de la simbólica de la centralidad. Pero también, estas distintas propuestas de lecturas me permiten reflexionar sobre la imposibilidad de finitud de cualquier área de conocimiento, incluyendo la interpretación bíblica. Como bien afirma Raúl Fornet Betancourt (Fornet Betancour 2007, p. 13) “...en cualquier área de experiencia o conocimiento del ser humano, la finitud humana significa un estar obligados al ejercicio o la praxis de la tolerancia, que es también un ejercicio de consulta y escucha del otro", esto para decir, que no existe la lectura de la biblia, sino las experiencias de interpretación de la Biblia desde un horizonte de sentido. Frente a lo expuesto anteriormente, puedo afirmar que la herencia pedagógica con relación a la lectura de la biblia en América Latina y Caribe se inscribe entre la imposibilidad de finitud, que refleja un pensamiento simplista, sustentado por el positivismo. Apoyada en Denisse Najmanovich (2010), destaco que se trata de un pensamiento con el cual el mundo se presenta como algo estático, la interpretación del texto como algo fijo, y el quien lee el texto como algo separado y excluido del propio texto, una persona 
sola y sin ningún vínculo social. Y la expresión compleja que revela la multiplicidad como experiencia fundante en el quehacer de una lectura de la Biblia que no se conforma con un ampliar el enfoque de la teología de la liberación o de la lectura popular de la Biblia. Sino un cambio de mirada que permite, un accionar interpretativo, una pedagogía que, desde el espacio y el vínculo de las comunidades o los colectivos de mujeres, negras e indígenas, jóvenes, vuelve a las personas responsables de sus propias vidas y sus transformaciones.

Se trata de una pedagogía que va adquiriendo nuevos significados. Que además se crea desde la idea de lo vincular, valoriza a las mismas personas que leen el texto, al mismo nivel que el propio texto, permitiendo con esto romper con lo estático, intocable, con lo ya dado de las interpretaciones tradicionales, que muchas veces, inclusive, vestidas de científicas, por emplear, por ejemplo, métodos como el histórico-crítico no son más que interpretaciones legitimadoras de un paradigma patriarcal dominante. Lo que sugiere que se plantee un mirar la historia del texto, así como la historia fuera del texto, donde se tenga en cuenta, por ejemplo, las historias de poder de las mujeres y otros grupos en condiciones de vulnerabilidad.

Es por esto, que Elisabeth Schüssler (1989, p. 23) destaca la importancia de analizar la historia de la Biblia revelando críticamente la historia patriarcal y reconstruir la historia de las mujeres en el cristianismo. En este sentido, vale recordar la propuesta de la pedagogía moderna que habla de valorizar y no castigar al error como estrategia de aprendizaje. Es en este sentido, que ubico también el tema de la herencia, pues no pretendo referirme solamente a algo que sucedió. La lectura de la Biblia, desde la perspectiva latinoamericana, por ser una propuesta de interpretación comunitaria - nacida en las comunidades de base y otros colectivos - afirmo con Michel Maffesoli (Maffesoli, 2000, p. 114) que:

“...la "memoria colectiva" (M. Halbwachs), el habitus (M. Mauss) pueden ser este tipo de forma en donde entren en composición a la vez los arquetipos y las diversas intencionalidades que permitan ajustarse a estos arquetipos, habitarlos en cierta manera. Éste es el espíritu de grupo, el espíritu del clan, cuya sinergia o yuxtaposición producen el espíritu del tiempo".

Me refiero, entonces, a una herencia pedagógica que se ha irradiado hasta provocar que las personas que realizan la lectura o la interpretación se abran a lo que están haciendo en común, interpretar la Biblia desde los intereses y la vida del pueblo más vulnerable, dígase: mujeres y hombres, de muchas dimensiones, de muchas opciones, de muchos colores. Personas que consideran la apertura de diálogo, buscando libertad y comprensión crítica y caminando hacia la transformación de los mundos vividos. Desde esa situación me atrevo a pensar sobre el conocer, es decir, intentando leer e interpretar los textos bíblicos haciendo surgir conocimiento. 


\section{Sobre la epistemología que emerge de los estudios bíblicos -}

...no estamos viviendo un mero cambio de modelos, teorías y paradigmas sino una verdadera mutación de nuestras formas de vivir la relación de conocimiento. (Najamanovich, 2010)

Durante mucho tiempo se ha impuesto una mirada a los textos bíblicos, una interpretación, movida por un paradigma de la 'verdad', de distinciones calificadas de la lectura fiel y la que no lo son. Esta realidad me hace recordar a Boaventura de Souza Santos, cuando afirma:

"...el pensamiento occidental moderno es un pensamiento abismal. Este consiste en un sistema de distinciones visibles e invisibles. Las invisibles constituyen el fundamento de las visibles y son establecidas través de líneas radicales que dividen la realidad social en dos universos, el universo "de este lado de la línea y el universo "del otro lado de la línea". La división es tal que "el otro lado de la línea" desaparece como realidad, se convierte como no existente, y de hecho es producido como no existente. No existente significa no existir en ninguna forma relevante o comprensible del ser."

Desde ese paradigma o sistema de pensamiento, muchas veces de forma violenta, se imponen formas de pensar y actuar frente a la vida. $Y$ no sólo se deslegitiman las interpretaciones otras, sino que la propia Biblia es utilizada como instrumento de discriminación o división. Frente a estas distinciones, que no son más que fragmentaciones del pensamiento y del saber, propongo una epistemología del otro lado de la línea, con lo cual pretendo nombrar o reconocer otros lugares, otros sentidos. De esa forma, visualizo las interpretaciones de la Biblia que se han planteado y continúan planteándose desde las márgenes. Es justamente, ese planteamiento que me permite transitar, del creer o no en las distinciones que han sido creadas, a pensar y a nombrar eso que pienso, de otras maneras, desde otros lugares, con otros sentidos y significados. Por lo tanto, provocar otros aprendizajes.

Es importante reconocer que las acciones que promueven procesos de aprendizajes no están exentas de construir conocimiento, remiten a pensar sobre el conocer. La interpretación de la Biblia implica producción de conocimiento. Al pensar sobre el conocer, es decir sobre el conocimiento que produce la lectura e interpretación de los textos bíblicos, entramos al campo de lo epistemológico. Por lo tanto, puedo afirmar que la lectura de los textos promueve y se hace desde decisiones epistemológicas, que están motivadas por distintos tipos de sistemas de pensamiento. En este sentido Irene Vasilachis (2006, pp. 46-47) propone hablar de reflexión epistemológica,

“...lo cual a diferencia de la epistemología no intenta ser una disciplina acabada...constituye una actividad creadora, que se renueva una y otra vez... 
lejos de buscar reglas comunes a los distintos procesos de conocimiento, la reflexión epistemológica intenta dar cuenta de las dificultades con las que el que conoce se enfrenta cuando cambian las características de aquello que intenta conocer, o cuando aun no siéndolo, no pueden ser, en todo o en parte, registradas, observadas con las teorías y/o conceptos existentes y con las estrategias metodológicas disponibles"

Para pocas personas es secreto que muchas mujeres cuando tienen la oportunidad de estudiar Biblia o Teología, generalmente, lo hacen dentro de los marcos epistemológicos del sistema patriarcal de la sociedad, presente también en las diferentes instituciones. En distintas ocasiones autoras como Ivone Gebara han señalado que a las mujeres se nos van largas horas escuchando a hombres (sacerdotes, pastores, profesores) exponer todo lo que saben sobre el significado de Dios, de un texto bíblico o de la Biblia en general, sobre los métodos "autorizados" para este estudio, etc. Inclusive, los textos básicos que debemos estudiar son los de autores. Por eso, una lectura de la Biblia crítica y feminista, además de traer a la superficie las memorias de mujeres, desvenda las historias androcéntricas y patriarcales con que el texto bíblico está construido. No aceptamos los textos bíblicos como historia, pero sí como construcciones históricas y culturales que no son la representación de las historias ni las culturas humanas. En fin, una hermenéutica bíblica crítica feminista, desarrolla modelos interpretativos a través del diálogo entre memorias antiguas de mujeres y hombres con sus cuerpos, sueños y esperanzas de vidas actuales. Por eso, es una lectura que invita a la imaginación, o re-imaginación de las historias de mujeres visibilizadas e invisibilizadas dentro del texto (Schüssler, 1989).

Es así que, desde una reflexión epistemológica, me permito afirmar que el texto bíblico significa más de lo que denota y evoca, en quienes han estado y están dispuestas a prestarles atención a otras imágenes, memorias y cosas deseadas, pérdidas o nunca captadas o entendidas del todo. Desde el paradigma positivista, frecuentemente se hacen lecturas simplistas que evocan el pensamiento único. Se han leído e interpretado los textos bíblicos, se han instaurado personajes anónimos que se han instituido a sí mismos en una posición de control. Se puede afirmar que, fuera de la absurda pretensión de cuantificar las experiencias, han sido todavía pocas las personas que deciden descifrar los códigos, descubrir aquello que puede tener significado desde el lugar donde están ellas mismas practicando la lectura, y que puedan apropiarse de visiones y perspectivas legítimamente suyas. Por eso, valoro las propuestas de lecturas otras que se atreven a romper con la simplicidad y transitar por caminos sin planos o mapas específicos, pero dando formas a procesos imaginativos que se generan en las interacciones cotidianas. Y con esto, como afirma Maxine Greene (2005, p. 81), permitir que quienes leen "busquen por sí mismos más allá de lo real y jueguen con posibilidades todavía por explorar". 
La propuesta de interpretar la Biblia desde los intereses y la vida del pueblo empobrecido, excluido, pero también desde la vida, concretamente, de las mujeres, refleja una epistemología que se considera y se genera a partir de estos grupos como centro de la lectura. Y desde esa centralidad del pueblo y de forma particular de las mujeres y la integralidad de su vida, se construye una pedagogía dinámica que resulta no sólo en diálogo y aprendizaje, sino también en propuestas transformadoras de relaciones. En este sentido, se puede afirmar que la herencia pedagógica de la lectura popular de la Biblia que afecta e impulsa una manera de pensar que la identifico como política, porque lejos de contaminar y "dañar" el proceso de lectura e interpretación, ayuda a convertirlo en un poderoso agente de transformación, tanto de las personas que leen o interpretan como de la realidad en la que viven.

Lo dicho anteriormente, rompe con la idea de una lectura de la Biblia desde la fragmentación de pensamiento, en el sentido, que va más allá del campo de lo religioso evidenciando ámbitos sociopolíticos que la han creado y que por lo tanto también las genera, fuera de ella misma. Es así que, desde hace un tiempo, me atrevo a proponer la lectura de la Biblia desde una mirada compleja. Esta mirada transita de privilegiar la simplicidad de lo unívoco, de pensar el texto anclado en su contexto, a una forma de cuestionamiento e interacción de éste con el entorno y la manera de pensar, vivir y soñar de quien la lee. Se trata de una mirada compleja, que como afirma Denise Najmanovich (2008, 77): "la complejidad no es una meta a la cual arribar sino una forma de cuestionamiento e interacción con el mundo; constituye a la vez un estilo cognitivo y una práctica rigurosa que no se atiene a "estándares" ni a "modelos a priori".

En este sentido, la lectura popular de la Biblia, desde el método, ver, juzgar, actuar, que sugiere ver la situación del pueblo y sus problemas, juzgarlos con la ayuda de la tradición bíblica y de las iglesias, con lo que se reconoce que la palabra de Dios ya no esté sólo en la Biblia, provocando una manera nueva de actuar (Mesters, 2012), desde un abordaje complejo, el cual no admite separaciones absolutas, sino relativización de la simplicidad, o más bien, apunta a considerar la relación de lo simple con lo complejo de la propia vida de las personas, pues trata de interacciones. En este sentido, la acción de 'ver' se puede enriquecer cuando, al mismo tiempo, se pregunte por el cómo, lo que implica no sólo ampliar la mirada, sino cambiarla. Entonces, no sólo se trata de ver el pueblo y sus problemas, sino de prestar atención a las distintas formas de estar temporal y espacialmente en el mundo, lo cual se genera en las interacciones que provocan y enfocan nuevos planos de realidad. Como bien afirma Denise Najmanovich 2005, p. 49) "desde la perspectiva clásica las interacciones resultaban invisibles, ya que el tamiz metodológico-conceptual no permitía captarlas".

El poder pensarse y descubrirse parte de una red hace posible la formulación de nuevas interrogantes, con las cuales es posible no sólo 
'juzgar' la situación, sino dar cuenta de las dificultades encontradas tanto dentro de los textos como fuera de ellos, es decir, en la propia experiencia vital. Los problemas en la vida del pueblo se descubren en las interacciones y, al mismo tiempo, descubre que la tradición bíblica y las iglesias no hablan por sí mismas. El propio texto bíblico y la palabra e imágenes de Dios presente revelan tramas que han sido construidas desde miradas particulares hechas universales y asumidas como tales. Y más todavía, el acto de 'ver' está entrelazado con las condiciones constitutivas de quien mira, con su propia historia. Al entender de Humberto Maturana $(1990,63)$, "la historia de un ser vivo es una historia de interacciones que provocan cambios estructurales mutuos entre el medio y el sistema vivo y el sistema vivo y el medio". En este sentido, me atrevo a plantear la limitación del método ver, juzgar y actuar cuando pretende tratar "la situación del pueblo y sus problemas", como algo externo el propio pueblo, así como también considerar "la palabra de Dios" tanto dentro como fuera de la Biblia, como algo dado, que el único cuidado a tener es la de ser manipulada: "una lectura más liberadora y más ecuménica, impidiendo que la Palabra de Dios fuese manipulada para legitimar la opresión y la explotación del pueblo" (Mester y Orofino, 2012).

Considero que la lectura de la Biblia, como productora de conocimiento, como señalé en párrafos anteriores, debe ser estudiada y reflexionada desde la perspectiva de lo vincular, es decir, desde distintos modos de interacción, pues como bien afirma Denise Najmanovich (2008, p. 87) "pensar desde lo vincular es un modo de interacción, una actividad poiética (productiva y poética) que deja una estela en su navegar: el conocimiento". De ahí la importancia de proponer y reflexionar sobre formas novedosas de abordajes bíblicos, entendida éstas como prácticas no solo pedagógicas, sino también epistemológicas. Estas formas no sólo me permiten ver los textos bíblicos de manera más amplia, con lo cual consigo prestar atención a otros rostros, a otras situaciones; sino que implica cambiar la propia mirada en las formas de abordar el texto para una mirada compleja, lo cual me permite, primero, entenderlo como un tejido de constituyentes heterogéneos inseparablemente asociadas, y segundo, puedo constatar las acciones, interacciones, retroacciones, determinaciones, que constituyen tanto el texto bíblico como quien lee desde su propio entorno también complejo. Este cambio de mirada promueve las miradas críticas y complejas sobre los estudios bíblicos tradicionales, pero también sobre las enseñanzas y aprendizajes sobre Dios o, más bien, sobre las experiencias de Dios en la vida de las personas. Es de esta forma, que vengo insistiendo desde trabajos anteriores, que nuevas maneras de abordar los textos bíblicos tienen que ver con no perder de vista la realidad del tejido fenoménico en el cual estamos y que constituye nuestro mundo (Ventura 2013). 
En ese sentido, las realidades actuales, que exigen pensar en desigualdades, exclusiones, pero también en los movimientos de resistencia, en las nuevas propuestas pedagógicas, en las nuevas preguntas hechas, por ejemplo, por las mujeres, que cuestionan el pensamiento y las formas patriarcales y dualistas de organizar la sociedad y la iglesia, todos estos elementos tienen que estar a la mano para los nuevos abordajes bíblicos. Los estudios de la Biblia deben ser hechos fuera de normas, lejos de los conceptos reguladores impuestos por métodos rígidos vaciados de criticidad del lugar social desde donde se lee. Pero, más todavía, la propuesta de abordar la Biblia de forma diferente, nueva, dice sobre la imposibilidad de limitar la experiencia de leer e interpretar la biblia a una única forma. Al tiempo que tiene una intención propositiva que va de lo propiamente epistemológico a lo social, político y cultural. Entonces, recobran sentido el desde dónde se lee la biblia, quién o quiénes leen, para qué se lee. Estas preguntas son fundamentales para poder evaluar no solamente la retórica de los textos bíblicos, sino también a quien interpreta y desde qué lugar social y epistémico se realiza. (Ventura, 2013).

Con frecuencia, en nuestras trayectorias como estudiosas/os de los textos bíblicos, se van perdiendo las capacidades de observar y conceptualizar el juego de interacciones, incidencias, dependencias, contradicciones que se dan al interior del texto y fuera, es decir en los contextos de quien lee, así como en los entornos subjetivos, individuales, grupales. Hacer una lectura de la Biblia desde esas interacciones provoca cambios de escenario, de dinámicas de relaciones con el texto, de sentidos del propio texto. Entonces, se va a poder observar que, por ejemplo (para hablar desde un texto concreto), en Éxodo 1,8-22: la relación de las mujeres parteras con su Dios, no es una relación de "miedo" o de "obediencia ciega", sino que se trata de una interacción que permite a esas mujeres descubrir la vida como valiosa y, por lo tanto, defenderla. Esto, por apuntar a un texto muy conocido, cuyas lecturas más frecuentes se encaminan a una interpretación que no permite cambiar la mirada bíblicoteológica de un paradigma que además de sustentar una doctrina única, homogeneizadora, autorizada por un invisible y omnipresente dios, vigilante de lo que se sale de normas preestablecidas y que además está en conflicto con otro "dios" - faraón- , imposibilita a las personas que leen los textos bíblicos a ir más allá de posiciones teológicas que están más interesadas en las normas que en la vida. Por eso, en esa forma de abordar los textos bíblicos, las parteras son identificadas como "temientes de dios", en vez de como defensoras de vida y por eso su interacción con dios (Ventura, 2013).

Con esta propuesta de abordaje de los textos bíblicos, me encamino por una crítica a la visión fragmentada del mundo, la cual tiene serias implicaciones en diferentes aspectos de la vida. Es esta la visión con la que entramos, con frecuencia, a leer los textos bíblicos. Una visión 
que considero traiciona la propia intención de la Lectura Popular de la Biblia que plantea la relación entre Vida y Biblia. Al suponer la vida de las personas fuera de las interacciones que presentan los propios textos quebramos el dinamismo del texto y sus posibilidades de ser un medio de diálogo para entender los propios niveles de relaciones desde donde se lee. Por eso, no me canso en proponer la interacción, la interrelacionalidad, interconexiones o como nos parezca bien llamarla, como clave de lectura con la cual puede relativizarse la simplicidad y descubrir, por medio de la lectura del texto, la reconfiguración global de las formas de producir, validar y compartir el conocimiento que se produce con la Biblia. Y más todavía, poder proponer formas de convivir más liberadoras.

Es así que, desde esa clave me aproximo también a textos como Gn 1-2, un texto fundante, en el sentido que ha determinado uno de los imaginarios más conocidos sobre Dios - el Dios creador - y puedo afirmar "que la acción de la creación allí planteada, representa una acción en la que se apunta a elementos clave como la diversidad en una constante interacción para dejar transparentar el Todo. En este sentido, la interrelacionalidad es una propuesta teórica y práctica que nace de las exigencias que nos plantea la conciencia de la diversidad cultural que caracteriza el mundo de hoy, pero también de la diversidad en el universo, en la creación misma (Ventura 2011, pp. 4-12). En este sentido, Ute Seibert Cuadra (2003, pp. 406-421), afirma que leer la Biblia con ojos de mujer es una tarea compleja, porque no se trata de simplemente "ampliar" el enfoque de la teología de la liberación o de la lectura popular de la Biblia, se trata de una propuesta radical, en el profundo sentido de la palabra, una propuesta que toca las raíces de nuestra manera de mirar y de percibirnos nosotras mismas, al mundo y al cosmos.

Pero también destaco Números 11, un texto en el que, desde las propuestas de lecturas, sean ellas tradicionales o de las llamadas liberadoras, se reconoce a Moisés como líder que revisa y expande la ley de dios, pero que jamás se cuestiona no sólo en su forma de liderazgo negativo para los tiempos contemporáneos, sino que también se ignora la fuerza del pueblo dentro del texto que cuestiona y reclama la propia ley de dios. Desde la complejidad en su propuesta de multidimensionalidad, interacción e interrelación, no podría de dejar de ver esas otras aristas del texto, más allá de la propuesta teológica que está sustentando. Es con lo que representa el 'otro lado de la línea' que puedo cambiar de mirada y hacer propuestas significativas desde los grupos que por su situación de vulnerabilidad "gritan pidiendo ayuda..., pidiendo carne para comer" (Nm 11:2,13), provocando con esto construir propuestas que sugieren cambio de estructuras (Nm 11,16). Y es ahí que toma fuerza esta propuesta de lectura en ser una posibilidad, entre tantas, de interpretar los textos bíblicos desde otros espacios, desde otras miradas que propugnan cambios no sólo en el pensar, sino también en el hacer en el mundo. 


\section{A modo de in-conclusión: \\ desafío pedagógico en una lectura de la Biblia desde un abordaje complejo}

"Lo que necesitamos saber está en el mundo, no en los libros ni en la escuela" (Fulghum, 2004, p. 89)

La finalidad de la acción pedagógica, en la experiencia de interpretación o de lectura de la Biblia es la liberación. Este fin sugiere un posicionamiento ético compromiso sugiere una Las complejas circunstancias en las que se inscribe el quehacer pedagógico en la sociedad contemporánea, provocan pensar la lectura de la Biblia como un proceso de aprendizaje. De hecho, la propia propuesta de Lectura Popular de la Biblia conlleva conocer la biblia y la vida, formar comunidad y servir (Mesters y Orofino, 2012, p. 21). Estos aspectos podrían considerarse definitorios para una pedagogía que provoque aprendizaje. Para lograrlo, y parafraseando a Francisco Gutiérrez (2011, p. 27) es necesario "pasar de una comunidad de enseñantes a una comunidad de aprendientes", y como comunidad está centrada en el trabajo colaborativo que conozca de su vida cotidiana y del mundo para poder conocer de la biblia, teniendo en cuenta que la noción de común, desde un pensamiento complejo, no disocia la singularidad.

Desde una perspectiva epistemológica compleja para relacionarnos con el texto bíblico, de una forma liberadora, se propone y promueve aprendizajes que se construyen en el mundo y con los otros. Es en ese sentido, que la lectura de la Biblia se ubica en los espacios vinculares. Porque no es una interpretación que se hace de forma aislada ni para imponer ni imponerse, sino que se genera en forma conjunta. Escuchando todas las voces y sus sentires frente al texto. Denisse Najmanovich $(2008,87)$, refiriéndose a la importancia de pensar en red, en la modernidad liquida, advierte que "desde una perspectiva vincular es posible gestar respuestas muy diferentes al "yo pienso" cartesiano y comenzar a pensar el sujeto del pensamiento como un 'nosotros'".

Es justamente, esto lo que se prioriza o se debe priorizar en la experiencia de lectura de la Biblia, la generación del "nosotros/as", donde ese "nosotros/as" mediante la relación de afecto con el texto y entre cada una y cada uno, se aprende! Por lo tanto, me refiero a una pedagogía de afecto, de ternura. Como bien afirma Hugo Assmann (2002, p. 28) "el ambiente pedagógico tiene que ser un lugar de fascinación e inventiva: no inhibir sino propiciar la dosis de ilusión común entusiasta requerida para que el proceso de aprender se produzca como mezcla de todos los sentidos".

Esto me hace recordar el propio Jesús de Nazaret, quien se deja afectar siempre por los otros y sus circunstancias, aprende, se transforma 
y transforma (Mt 15,21-28; Mc 7,24-30). En esa experiencia, Jesús no sólo aprende de "la otra", la mujer, la extranjera, sino que se afecta, hace "nosotros" con ella; la afecta, comparte el pan. Lo que ocurre en el texto es un ejemplo de lo que provoca una pedagogía del afecto, de la ternura. Al final de la narración, Jesús aprende a sentir de otro modo, "por haber hablado así, vete tranquila" (Mc 7, 29b). En este sentido, es una lectura que tiene como principal clave pedagógica el propio cuerpo de quien lee. Un cuerpo que se define en la trama de afectación de las relaciones humanas y el mundo interior de valores y significados. Al entender de Carlos Aldana Mendoza (2007, p. 71):

"la transformación del mundo empieza por una revolución en la cual las emociones y las sensibilidades ocupen el espacio más importante en la conducción de nuestras vidas, relegando la hegemonía de la racionalidad..."

Es justamente, en esa trama de afectación seres humanosmundo, donde se construyen los saberes que se necesitan para un estar transformador en el mundo. La frase con la que abre esta sesión no quiere ser más que una provocación a aceptar la Biblia, primero, fuera de lo institucional y desde un pensar complejo que permita interactuar con el texto, su contexto, sus visibilidades e invisibilidades y hacer emerger aprendizajes liberadores y transformadores. "Lo que necesitamos saber está en el mundo", una afirmación sugerente que me hace recordar de nuevo a Gustavo Gutiérrez con su afirmación "la teología es acto segundo". Sin embargo, un abordaje de la Biblia, desde la complejidad me permite pensar que lo que necesito saber está en el mundo y en la Biblia. Dicho de otra manera, el conocimiento que surge de un estudio bíblico desde la perspectiva de la complejidad es producto de lo que está en el texto junto con lo que está fuera. O lo que es lo mismo, no consigo separar el texto de quien lo lee. Si puedo, como mujer aproximarme al texto de la mujer extranjera y Jesús y lograr descubrir las interacciones es porque hay un fuera del texto que me permite ver a la mujer a través de mi propia vida, y hacer emerger conocimiento, aprendizaje. Soy yo con el texto y el texto conmigo.

Un desafío que se inscribe en una metodología no sólo de cambio, sino de verdadera mutación de nuestras formas de pensar y de vivir la experiencia de aprendizaje (Najmanovich, 2010). Y destaco, experiencia de aprendizaje, porque el aprendizaje tiene que ver con el modo de vida. La palabra aprendizaje viene de aprehender, es decir, de tomar, de la captación de algo. El aprendizaje no es la captación de nada, es el transformarse en un medio particular de interacciones recurrentes. Desde un espacio interreligioso el aprendizaje me permite el dominio de lo religioso en la interacción para crear un espacio de aceptación del otro, no de su negación, lo que me permitirá tanto crecimiento intelectual como 
ético (Ventura, 2010, p. 15). Es así como puedo afirmar, que desde un estudio bíblico, donde emerge conocimiento, producto de la interacción entre quien lee y el propio texto, no hay negación de ninguno ni del texto ni de quien lo lee. En esa interacción se produce conocimiento, el cual siempre va a ser valorativo. Por lo tanto, está presente la noción de ética, que confirma la existencia de quien lee.

Y me refiero a los aprendizajes que surgen de estudios bíblicos desde abordajes complejos. Como he señalado, a lo largo de este trabajo, este tipo de abordaje, al definirse por medio de las interacciones, la experiencia de comunidad es una clave importante, no para cerrarse a hablar de sí misma, sino una comunidad desde la que se habla afectada y afectando el entorno en el que se inscribe. En este sentido, se trata de una pedagogía que permite visibilizar no sólo a las personas, dentro o fuera del texto bíblico, sino también visibilizar los vínculos, las interacciones que permiten detenerse y prestar atención tanto a quien le desafía como lo que desafía, porque sin el otro, la otra, no puede avanzar. Es, entonces, en la experiencia comunitaria, como mediación pedagógica que se da la comunicación que permite el aprendizaje y transforman. ¡Y es ahí, donde los estudios bíblicos tienen sentido liberador!

Y hoy puedo retomar lo que hace algún tiempo vengo señalando:

... la propuesta de una educación interrelacional, como proceso de aprendizaje, se afirma como diversidad de cambio y como una experiencia donde prima la cooperación. Luego, es importante "contar", en el sentido de avanzar, de no quedarse parado, de compartir la experiencia y los efectos de las interrelaciones. (Ventura, 2009, p. 20) 


\section{Bibliografía de referencia}

Aldana, Carlos Mendoza (2007), La revolución del sentir - nuestro derecho a transformar el mundo, Barcelona: Intermón Oxfam.

Assmann, Hugo (2002), Placer y ternura en la educación - hacía una sociedad aprendiente, Madrid: Narcea S.A. De Ediciones.

Cañaveral, Aníbal (2011), "Leer la Biblia en clave campesina" en Revista Pasos n. 151, San José (Costa Rica): DEI, pp.31-39.

Capra, Fritjof (2008), El punto crucial - ciencia, sociedad y cultura naciente, Buenos Aires: Editorial Troquel

Fornet Betancourt, Raúl (2007), Interculturalidad y Religión - para una lectura intercultural de la crisis actual del cristianismo, Quito (Ecuador): Ediciones Abya Yala,

Freire, Paulo (1996), Pedagogia da autonomia - saberes necessários a prática educativa, São Paulo: Paz e Terra.

Fulghum, R. (2004). Las cosas que aprendí en el kinder. Bogotá, Colombia: Planeta.

Gebara, Ivone (1994), Teología a ritmo de mujer, Madrid: Paulinas

Greene Maxine (2005), Liberar la imaginación - ensayos sobre educación, arte y cambio social, Barcelona: Editorial Graó

Gustavo Gutierrez (1975), Teología de la liberación, Salamanca (España): Ediciones Sígueme.

http://www.claiweb.org/ribla/ribla1/2\%20lectura\%20popular\%20de\%20 la\%20biblia.htm (consultado el 28 de febrero 2014)

Izidoro, Jose Luiz (2013), Identidades e fronteiras étnicas no cristianismo da Galácia, São Paulo: Paulus

Maturana, Humberto (1990), Biología de la cognición y epistemología, Temucho (Chile): Ediciones, Universidad de la Frontera.

Mena López, Maricel (2005/1), “Hermenéutica negra feminista - de invisible a intérprete y artífice de su propia historia", Quito (Ecuador): RECUE, San José (Costa Rica): DEI, p.130-134.

Mesters, Carlos; Orofino, Francisco (2012), Sobre la Lectura Popular de la Biblia, http://biblioteca.clacso.edu.ar/subida/Costa_Rica/dei/ uploads/20120706110824/lectura.pdf.ori (consultado el 25 febrero, 2014)

Morin, Edgar; Ciurana , Emilio Roger; Motta, Raúl D. (2009), Educar en la era planetaria, Barcelona: Editorial Gedisa

Najmanovich, Denise (2005), El juego de los vínculos - subjetividad y redes, el mundo en mutación, Buenos Aires: Editorial Biblos,

Najmanovich, Denise (2008), Mirar con nuevos ojos - nuevos paradigmas en la ciencia y pensamiento complejo, Buenos Aires: Editorial Biblos. 
Najmanovich, Denise (2010), Epistemología y Nuevos Paradigmas en Educación. Educar y aprender en la sociedad-red,

http://www.rizoma-freireano.org/index.php/epistemologia-y-nuevosparadigmas-en-educacion-educar-y-aprender-en-la-sociedad-red-dra-denise-najmanovich, (consultado el 26/2/2014)

Richard, Pablo, 1992, (1998), “Lectura Popular de la Biblia en América Latina, Hermenéutica de la liberación" en Ribla, no.1, San José (Costa Rica): DEI, pp30-34.

Santos de Souza, Boaventura (2010), Descolonizar el saber, reinventar el poder, Editorial Trilce, Asunción (Uruguay),

Schüssler Elisabeth Fiorenza (2000), Cristología feminista crítica - Jesús hijo de Miriam, profeta de la Sabiduría, Madrid: Editorial Trotta.

Schüssler, Elizabeth Fiorenza (1989), En memoria de ella, Bilbao: Desclée de Brouwer.

Seibert, Ute Cuadra (2003), "Leer la Biblia con ojos de mujer - aportes para una lectura feminista de la Biblia en América Latina" en Teología y género, La Habana: Editorial Camino, pp.406-421.

Tamez, Elsa (2004), Luchas de poder en los orígenes del cristianismo - un estudio de la 1 ${ }^{a}$. Carta a Timoteo, San José (Costa Rica): DEI

Vasilachis, Irene (coord.) (2006), Estrategias de Investigación Cualitativa, Barcelona: Editorial Gedisa

Ventura, María Cristina (2004), “Un cushita habla ¡como el Dios del profeta! - Una lectura de Jeremías 38,7-13 en Ribla n.54, Quito (Ecuador): RECUE, pp.61-74.

Ventura, Tirsa (2009), “y atravesó del otro lado - desafíos para una educación interrelacional en el actual contexto latinoamericano y caribeño a partir de mc 5, 1-20" en Revista Pasos, n. 143, San José (Costa Rica): DEI pp. 14-20

Ventura, Tirsa (2011), “La interrelacionalidad como principio hermenéutico - para leer la Biblia más allá de la fragmentación" en Revista Pasos, San José (Costa Rica): Editorial DEI.

Ventura, Tirsa (2013), “Educación Teológica y nuevas formas de abordar los textos bíblicos" en Servicios pedagógicos y teológicos, http://www. serviciospt.org/art/174-et-y-biblia (consultado el 9 de marzo, 2014). 